\title{
Long-term administration of IgG2a anti-NK1.1 monoclonal antibody ameliorates lupus-like disease in NZB/W mice in spite of an early worsening induced by an IgG2a-dependent BAFF/BLyS production
}

\author{
Edilberto Postól, ${ }^{1}$ André Meyer, ${ }^{2}$ \\ Fabíola Cardillo, ${ }^{2}$ Raquel de \\ Alencar, ${ }^{1}$ Daniel Pessina, ${ }^{2}$ Jorge \\ Nihei, ${ }^{2}$ Mário Mariano ${ }^{3}$ and José \\ Mengel $^{2}$ \\ ${ }^{1}$ Immunology Laboratory, Heart Institute \\ (INCOR), University of São Paulo, São Paulo, \\ ${ }^{2}$ Gonçalo Moniz Institute, Oswaldo Cruz \\ Foundation (IGM/FIOCRUZ), Salvador, Bahia \\ and ${ }^{3}$ Discipline of Immunology, Department of \\ Microbiology, Immunology and Parasitology, \\ Federal University of São Paulo, São Paulo, \\ Brazil
}

doi:10.1111/j.1365-2567.2008.02835.x Received 9 July 2007; revised 15 February 2008; accepted 20 February 2008. Correspondence: Dr J. Mengel, Gonçalo Moniz Institute, Oswaldo Cruz Foundation (IGM/FIOCRUZ), Rua Waldemar Falcão 121, Candeal, 40296-710 Salvador, Bahia, Brazil.

Email: jomengel@bahia.fiocruz.br

Senior author: José Mengel

\begin{abstract}
Summary
The role of natural killer (NK) $\mathrm{T}$ cells in the development of lupus-like disease in mice is still controversial. We treated NZB/W mice with antiNK1.1 monoclonal antibodies (mAbs) and our results revealed that administration of either an irrelevant immunoglobulin G2a (IgG2a) mAb or an IgG2a anti-NK1.1 mAb increased the production of anti-dsDNA antibodies in young NZB/W mice. However, the continuous administration of an anti-NK1.1 mAb protected aged NZB/W mice from glomerular injury, leading to prolonged survival and stabilization of the proteinuria. Conversely, the administration of the control IgG2a mAb led to an aggravation of the lupus-like disease. Augmented titres of anti-dsDNA in NZB/ $\mathrm{W}$ mice, upon IgG2a administration, correlated with the production of BAFF/BLyS by dendritic, B and T cells. Treatment with an anti-NK1.1 $\mathrm{mAb}$ reduced the levels of interleukin-16, produced by $\mathrm{T}$ cells, in spleen cell culture supernatants from aged NZB/W. Adoptive transfer of NK T cells from aged to young NZB/W accelerated the production of antidsDNA in recipient NZB/W mice, suggesting that NK T cells from aged $\mathrm{NZB} / \mathrm{W}$ are endowed with a B-cell helper activity. In vitro studies, using purified NK $T$ cells from aged NZB/W, showed that these cells provided helper B-cell activity for the production of anti-dsDNA. We concluded that NK T cells are involved in the progression of lupus-like disease in mature NZB/W mice and that immunoglobulin of the IgG2a isotype has an enhancing effect on antibody synthesis due to the induction of BAFF/ BLyS, and therefore have a deleterious effect in the NZB/W mouse physiology.
\end{abstract}

Keywords: BAFF/BLyS; Fc receptor; interleukin-16; natural killer T cells; systemic lupus erythematosus; Toll-like receptor

\section{Introduction}

Systemic lupus erythematosus (SLE) is a connective tissue disease associated with significant morbidity and mortality, related either to the disease itself or to complications of the treatment. The disease is characterized by antinuclear autoantibodies and multiorgan tissue injury, including immune complex glomerulonephritis. ${ }^{1}$ The disease can be induced experimentally in non-autoimmune mice by injection of cells, antigens or some inorganic compounds. ${ }^{1-4}$ Also, there is a particular combination of mouse strains, the $\mathrm{F}_{1}(\mathrm{NZB} \times \mathrm{NZW})$, that develops a disease characterized by lethal immune complex glomeronephritis and high plasma levels of anti-double-stranded
DNA (anti-dsDNA) antibodies. These antibodies have been reported to play a role in glomerular injury. ${ }^{5}$ The disease in $\mathrm{NZB} / \mathrm{W}$ mice resembles the lupus which occurs in humans, with severe glomerulonephritis. ${ }^{6}$

$\mathrm{CD}^{+} \mathrm{T}$ cells play an important role in the development of lupus in NZB/W mice because treatment with anti-CD4 monoclonal antibodies (mAbs) ameliorates the disease. ${ }^{7} \mathrm{CD}^{+} \mathrm{T}$ cells derived from lupus-prone mice have been shown to recognize nucleosomes and peptides derived from anti-DNA antibodies. ${ }^{8}$ Recently, it was reported that a subpopulation of $\mathrm{CD}^{+} \mathrm{T}$ cells that recognizes the $\mathrm{CD} 1 \mathrm{~d}$ molecule could contribute to the pathogenesis of lupus-like disease in mice. ${ }^{9}$ In addition, CD1d-reactive NK1.1 ${ }^{+} \mathrm{T}$ cells are involved in lupus-like 
disease in many different experimental systems. ${ }^{6,9-13}$ This T-cell lineage is notable for expressing the NK1.1 molecule, besides having a restricted repertoire constituted by the usage of T-cell antigen receptors (TCR) formed mainly by the $\mathrm{V} \beta 8$ chain in association with an invariable Va14J $\alpha 281$ chain. ${ }^{14}$ Natural killer (NK) T cells secrete large amounts of interferon- $\gamma$ and interleukin-4 upon in vivo or in vitro stimulation with anti-CD3 antibodies. ${ }^{14,15}$ These cells recognize phospholipids and glycolipids in association with a non-polymorphic, non-major histocompatibility complex (MHC) -encoded, MHC I-like molecule (CD1d) expressed on antigen-presenting cells. ${ }^{14,15}$ Recently, it was described that anti-CD1 blocking antibodies ameliorate lupus-like disease in NZB/W mice, whereas activation of CD1d-restricted $\mathrm{T}$ cells by a glycolipid ( $\alpha$-galactosylceramide) can aggravate the disease. ${ }^{6,13}$ These studies have also shown that NK T cells may have different functions in young and in aged NZB/ $\mathrm{W}$ mice. There is a report that the NK T-cell population in aged lupus-prone mice may use a different antigen repertoire, with TCR modified by the insertion of $\mathrm{N}$ additions in the invariant $\mathrm{V} \alpha$ chain. ${ }^{16}$ On the other hand, another study indicated that the in vivo activation of NK $\mathrm{T}$ cells ameliorates some aspects of lupus-like disease in mice. ${ }^{17}$ Furthermore, it has been shown that autoimmune and non-autoimmune mouse strains may develop more severe nephritis and large amounts of autoantibodies and lupus-like disease in the absence of ${\mathrm{V} \alpha 14^{+}}^{\mathrm{NK}} \mathrm{T}$ cells, as these mice age. ${ }^{11,18}$ Taken together, these studies suggest that NK $\mathrm{T}$ cells are involved either in the control of lupus-like disease in some experimental models or in the promotion of the disease in aged NZB/W mice.

Herein, we confirm and extend some of these results by taking a different approach. NZB/W mice were treated chronically with anti-NK1.1 mAbs from the age of 4 weeks. Our data support the notion that NK T cells have a pathogenic role in the development of lupus-like disease in aged NZB/W mice. In addition, we provide evidence to support a deleterious role for immunoglobulin G2a (IgG2a) and lipopolysaccharide (LPS) in the development of this disease by the induction of B-cell-activating factor/B-lymphocyte stimulator (BAFF/BLyS) secretion by cells of the immune system.

\section{Materials and methods}

\section{Animals}

Female $(\mathrm{NZB} \times \mathrm{NZW}) \mathrm{F}_{1}, \mathrm{C} 57 \mathrm{BL} / 6, \mathrm{BALB} / \mathrm{c}$ and $\mathrm{BALB} / \mathrm{c}$ $n u / n u$ mice from 1 to 9 months of age were bred and maintained under standard conditions in the mouse colony of the Department of Immunology, Institute of Biomedical Sciences, São Paulo or in the animal facilities of the Gonçalo Moniz Institute (IGM), Oswaldo Cruz Foundation (FIOCRUZ), Salvador, Brazil.
Protocols used in this study were approved by the Ethics Committees in Experimental Animal Models (Institute of Biomedical Sciences, University of São Paulo and IGM/FIOCRUZ).

\section{Enzyme-linked immunosorbent assays}

For detection of dsDNA-specific antibodies, sera were obtained from the different experimental groups by bleeding mice from the tail vein and were assayed by enzyme-linked immunsorbent assay (ELISA) against ds-DNA-sensitized plates (96-well flat-bottomed microplates; Nunc Inc., Rochester, NY). A goat anti-mouse (IgG + IgM)-biotin conjugate (Zymed Laboratories Inc., San Francisco, CA) was added at an appropriate dilution to detect total immunoglobulin. Streptavidin peroxidase (BD Biosciences, San Jose, CA) was used as tertiary reagent. One standard positive serum and one negative serum were used in every assay. Results are given in titres (reverse of the end-point dilution + SEM). For cytokine ELISAs, the levels of BAFF/BLyS and interleukin-16 (IL-16) were quantified using a two-site sandwich ELISA. Anti-BAFF/BLyS monoclonal and polyclonal antibodies were obtained from R\&D Systems (Minneapolis, MN). Anti-IL-16 monoclonal antibodies were from Invitrogen Corporation (Carlsbad, CA) (clone 14.1, used as capturing antibody for human/mouse IL-16) and R\&D Systems (biotin-conjugate polyclonal antihuman/mouse IL-16). Recombinant mouse BAFF/BLyS and human IL-16 were from R \& D Systems.

\section{Monoclonal antibodies, cells and other reagents for flow cytometry analysis}

H-129 (anti-CD4), H-57-597 (anti-pan $\beta$-chain), PK136 (anti-NK1.1), DX-5 (anti-NK), 2C11 (anti-CD3), R6-60.2 (anti-mouse IgM), RA3-6B2 (anti-B220), NIMR-4 (antiIA/IE) mAbs, labelled with phycoerythrin (PE), fluorescein isothiocyanate (FITC) or biotin, were used. For the biotin-labelled mAbs, PE-streptavidin, PE-Cy5-streptavidin or FITC-streptavidin was used as a second-step reagent, as indicated. All these reagents were purchased from eBioscience (San Diego, CA), BD Biosciences, Southern Biotechnology (Birmingham, AL) or Invitrogen Corporation spleen, liver and lymph node cells were isolated and placed in ice-cold $0 \cdot 15 \mathrm{~m}$ phosphate-buffered saline (PBS), pH 7.2 supplemented with 5\% fetal bovine serum (FBS) and $0 \cdot 1 \%$ sodium azide. Mononuclear liver cells were obtained by centrifugation on a $40-80 \%$ Percoll gradient (Pharmacia, Uppsala, Sweden). They were recovered from the interface and washed in PBS plus 10\% FBS. Staining was performed as previously described. ${ }^{19}$ Fc blocking was used throughout the staining procedure, as described elsewhere. ${ }^{20}$ After staining, cells were analysed using a FACScan (Becton Dickinson, San Jose, CA). A minimum of 10000 events was recorded per sample. 


\section{E. Postól et al.}

\section{Intracellular staining}

For IL-16 detection, cells were cultured overnight in complete medium without further stimulation. Brefeldin-A (Sigma, St Louis, MO) was added in the last $8 \mathrm{hr}$ of culture. Cultured cells were harvested, washed and resuspended at $2 \times 10^{6} /$ well in staining buffer (balanced salt solution containing $1 \%$ sodium azide and 5\% FBS). For BAFF detection, cells were not previously cultured and were stained as soon as they were obtained from the animals. For intracytoplasmic staining, cells were first stained with FITC-conjugated or Cy5-conjugated primary mAbs, as indicated, for $20 \mathrm{~min}$ at $4^{\circ}$ and then fixed in $2 \%$ paraformaldehyde for $30 \mathrm{~min}$. The cells were then washed and incubated in staining buffer containing $0 \cdot 1 \%$ saponin for $30 \mathrm{~min}$. Continuously exposed to saponin, the cells were then stained with PE-conjugated anti-murine BAFF or IL-16 mAbs (R\&D Systems and Invitrogen Corporation, respectively) for $30 \mathrm{~min}$ at $4^{\circ}$. After washing with staining buffer, the cells were washed again with staining buffer without saponin to allow membrane closure. A minimum of 20000 events was collected. Results were analyzed using flowjo software (Tree Star Inc., Ashland, OR).

\section{In vivo treatments}

The mAb treatments were performed as previously described. ${ }^{19}$ In brief, each mouse received $0.5 \mathrm{mg}$ of the protein-G-purified monoclonal anti-NK1.1 (PK136) by intraperitoneal (i.p.) injection, three times a week. The treatment was maintained during the experiments. The efficacy of the mAb in depleting the animals of $\mathrm{NK} 1.1^{+}$ and NK1.1 $1^{+} \mathrm{T}$ cells was ascertained by fluorescence-activated cell sorting (FACS) analysis, using a second anti$\mathrm{NK}$ mAb (DX-5). The reduction of NK $\mathrm{T}$ lymphocytes among liver mononuclear cells was approximately $80 \%$ after 1 week of treatment (supplementary information Fig. S1, panel A). As a control for the PK136 mAb treatment, protein-G purified mouse IgG2a (clone 5D11, anti-human carcinoembryonic antigen $)^{21}$ was given i.p., following the same protocol as the one used for the PK136 mAb. In some experiments, IgG2a (5D11) mAb was heat-aggregated, as previously described. ${ }^{22}$ This preparation was used as above. This IgG2a mAb did not produce any staining in thymocytes, spleen cells or bone marrow cells from NZB/W mice (supplementary information Fig. S1, panel B). Other control groups received PBS, protein-G-purified serum IgG (from $\mathrm{BALB} / \mathrm{c}$ mice) or another monoclonal antibody that recognizes dog monocyte/macrophage, belonging to the mouse IgG1 subclass (clone IH1). ${ }^{23}$ These antibodies were used as controls. In some experiments Toll-4 ligand (LPS, Escherichia coli 055:B5) from Sigma-Aldrich or Toll-2 ligand $\left[\mathrm{Pam}_{3} \mathrm{CSK}_{4}\right.$ (P3C)] from EMC Microcollections (Tuebingen, Germany) was injected i.p. at a dose of $2 \mathrm{ng} /$ injection every other day for a period of 4 weeks. Large amounts of sera were required for these experiments so several batches of mouse serum, collected over several years from BALB/c mice, were pooled. All batches were kept at $-20^{\circ}$ during the storage period. For the same reason, mice receiving polyclonal IgG were treated up to the end of the 6th month of age, only. Monoclonal antibodies were purified from ascitic fluid obtained in $\mathrm{BALB} / \mathrm{c} n u / n u$ mice as described previously. ${ }^{19}$

\section{In vitro cell depletion or enrichment}

B cells were obtained from spleen cells after incubation with the following biotin-labelled mAbs: anti-CD3 (2C11), anti-TER119 and anti-CD11b. These mAbs were from Invitrogen Corporation. The incubation was carried out at $4^{\circ}$ for $20 \mathrm{~min}$ in balanced salt solution (BSS) supplemented with $10 \%$ fetal calf serum. Spleen cells were washed four more times. For the depletion, a second incubation with streptavidin-coated Dynabeads (Dynal, Oslo, Norway) was carried out, according to the manufacturer's instructions. After two rounds of magnetic exclusion, the remaining spleen cells were used for in vitro assays. The efficacy of depletion was monitored by FACS analysis and the percentage of B-cell preparation was found to be above $90 \%$ when labelled with antiCD19-FITC and anti-CD1-PE (both from BD Biosciences) (supplementary information Fig. S1, panel C). For NK T-cell purification, a FITC-multisort kit from Miltenyi Biotec (Bergish Gladbach, Germany) was used, according to the manufacturer's instructions. First, liver and spleen FITC $-\alpha \beta^{+}$cells were positively sorted. Purified $\alpha \beta^{+}$cells (purity was usually above 90\%) were stained with antiNK1.1 biotin and positively sorted by using streptavidincoated microbeads from Miltenyi Biotec. The purity of NK $1.1^{+} \alpha \beta^{+}$cells was usually around $80 \%$ on FACS reanalysis (supplementary information Fig. S1, panel C).

\section{In vitro cell culture}

For interleukin measurements, pooled spleen cells from different experimental groups were cultured in RPMI1640 (Gibco, Grand Island, NY) supplemented with 10\% FBS (Hyclone, Logan, UT), $50 \mathrm{~mm}$ 2-mercaptoethanol and $1 \mathrm{mM}$ HEPES (complete RPMI) at a density of $5 \times 10^{6} \mathrm{cells} / \mathrm{ml} /$ well in 24 -well plates (Nunc), cultures were performed in triplicates and stimulated or not with $5 \mu \mathrm{g} / \mathrm{ml}$ of concanavalin A for 24 or $48 \mathrm{hr}$. Supernatants were collected and frozen at $-70^{\circ}$.

\section{B-cell-helper assay}

In short, titrated numbers of purified NK1.1 $1^{+} \alpha \beta^{+} \mathrm{T}$ cells were cultured with $4 \times 10^{5}$ B-cell-enriched population/ well from the indicated groups. The B-cell-enriched pop- 
ulation consisted of splenocytes depleted of $\mathrm{T}$ cells by streptavidin-coated magnetic beads, as described above. Cultures were performed in triplicate, in 96-well, flatbottomed plates (Nunc) in the presence of $2 \mu \mathrm{g} / \mathrm{ml}$ purified anti-CD3 $\mathrm{mAb}$ (clone 2C11), in a total volume of $200 \mu \mathrm{l}$ of complete RPMI-1640. Supernatants were collected 7 days later for the anti-dsDNA antibody ELISA.

\section{Cell transfers}

Purified NK1.1 ${ }^{+} \alpha \beta^{+} \mathrm{T}$ cells were obtained as above from a pool of spleens and liver mononuclear cells. Each recipient animal (6-8 weeks old) received $2 \times 10^{6}$ purified NK $\mathrm{T}$ cells, injected intravenously. Controls received no $\mathrm{T}$ cells and the same amount of PBS intravenously. Aged donor mice were 6-9 months old. Young donor mice were 1-2 months old. Usually, 10 donor mice were necessary to transfer cells to one recipient.

\section{Proteinuria evaluation}

Three individual samples from each mouse were obtained monthly. After collection, the protein level was determined using the Bradford reagent. Mice that had high proteinuria levels (above $100 \mathrm{mg} / \mathrm{dl}$ in, at least, two different samples) were considered positive for renal disease. Discrepant results among the three samples collected from the same animal (SEM $\geq 30 \%$ of the mean) were discarded and the data for those animals were not considered in the respective time points. The number of animals with validated proteinuria measurements therefore varies during the experimental observation period and does not correlate with the number of animals in the experimental group.

\section{Histological evaluation}

Nephritis severity was evaluated in the glomerulus by using grades based on the intensity and extension of the histopathological alterations: $0+$, kidneys without glomerular renal lesion; $1+$, lesions with minimal mesangial cellularity increase; 2+, lesions containing a significant increase in mesangial and glomerular cellularity; 3+, lesions characterized by glomerular inflammatory exudates and established capsular adhesion; and 4+, extensive formation of tubular aspect and glomerular architecture obliteration in more than $70 \%$ of the glomerulus. Only lesions graded as $3+$ and $4+$ were considered as a significant indication of disease. The slides were coded and all histological analysis was double blind.

\section{Statistical analysis}

Differences between experimental groups were analysed using Mann-Whitney tests, Tukey tests or Student's $t$-tests. Values of $P \leq 0.05$ were considered significant.

\section{Results}

Long-term in vivo administration of anti-NK1.1 IgG2a $\mathrm{mAb}$ halts the progression of lupus-like disease, whereas control IgG2a mAb accelerates disease onset

For in vivo treatment with IgG2a mAbs, we injected mice with anti-NK1.1, unrelated IgG2a (clone 5D11), polyclonal IgG or PBS (four groups, 20 mice/group). Figure 1(a) shows that the administration of mAbs of the IgG2a subclass (either anti-NK1.1 or an unrelated mouse IgG2a) increased the serum titres of anti-dsDNA in NZB/W mice shortly after the initiation of the in vivo treatment. In contrast, control groups receiving polyclonal IgG or PBS followed a different pattern, having levels of anti-dsDNA as high as those of mice that received IgG2a mAbs only after 9 months of follow-up. Groups of mice receiving IgG2a $\mathrm{mAb}$ also showed an increased frequency of mice with high proteinuria within 2 months of treatment initiation. However, after 6 months, the frequency of mice showing high proteinuria levels had stabilized and was lower than those of the other experimental groups in the group that had received anti-NK1.1 mAb (Fig. 1b). Control groups, receiving either PBS or polyclonal IgG, showed a delayed progression to renal disease when compared to IgG2a mAb-treated groups. However, the frequency of animals with high proteinuria levels increased progressively after 5 months in the group of animals treated with PBS. The group of mice receiving polyclonal IgG had lower frequencies of animals with high proteinuria levels up to 7 months later, but those frequencies were similar in both groups of mice after 8 months (Fig. 1b). Cumulative mortalities were also were significantly different in the different groups. Mortality was higher and precocious in the control group receiving $\mathrm{PBS}$, and was diminished in groups that were treated with anti-NK1.1 mAb or polyclonal IgG (Fig. 1c). To study the kidney histological lesions another four groups of mice were treated with anti-NK1.1 $(n=20)$, unrelated IgG2a (clone 5D11) $(n=23)$, polyclonal IgG $(n=10)$ or PBS $(n=15)$. Ten-month-old mice that survived the long-term treatment were killed and the kidney histological analysis was performed. Table 1 shows that about $75 \%$ of the mice had kidney lesions graded as $3+$ and $4+$ in groups treated with PBS or control IgG2a mAb. Sixty per cent of the mice treated with purified serum polyclonal IgG showed high-grade $(3+$ and $4+)$ kidney lesions by 10 months of age. However, only about $45 \%$ of the mice receiving anti-NK1.1 mAb had high-grade kidney lesions.

\section{IgG2a mAbs induce the production of BAFF/BLyS in $\mathrm{NZB} / \mathrm{W}$ mice}

As demonstrated above, in vivo administration of IgG2a $\mathrm{mAbs}$ induced rapid onset of lupus-like disease in NZB/W mice. BAFF/BLyS is probably one of the cytokines involved 

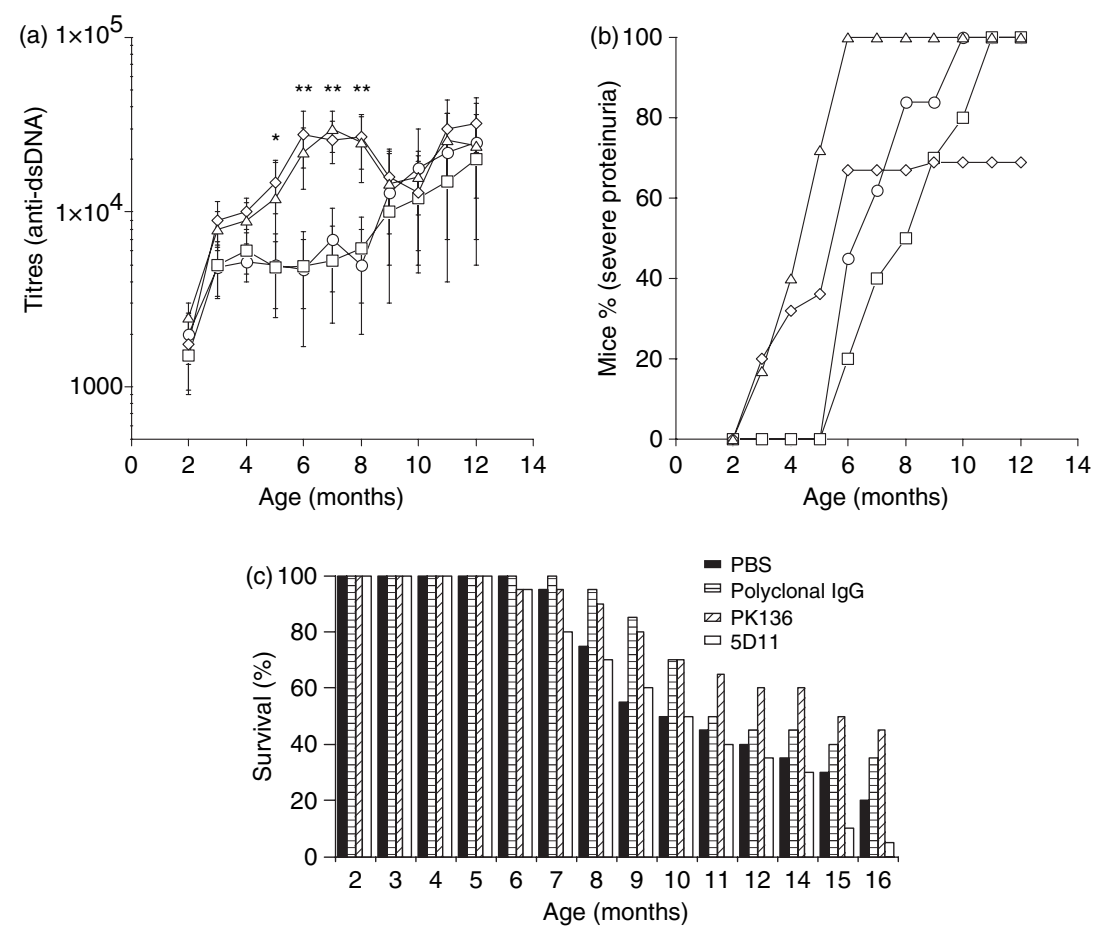

Figure 1. Long-term in vivo administration of anti-NK1.1 immunoglobulin G2a (IgG2a) monoclonal antibody (mAb) halts the progression of lupus-like disease, whereas control IgG2a mAb accelerates the onset of the disease. $(\mathrm{a}, \mathrm{b})$ The titres of anti-dsDNA and the percentage of mice with severe proteinuria were determined at the indicated age in the different NZB/W mouse groups [NZB/W mice are represented as follows: mice treated with phosphate-buffered saline (PBS), open circles; anti-NK1.1 mAb, open diamonds; control IgG2a mAb open triangles; polyclonal serum IgG, open squares]. Anti-dsDNA antibody levels are shown as titres, in which the average of the optical densities obtained with pooled sera from control mice (C57BL/6), diluted 1:100, was considered the end-point. The titre for each sample was expressed as the reciprocal of the highest dilution that produced an absorbance value higher than the cut-off value. Each point represents the mean of the titre values from mice that survived the indicated time period. Vertical bars represent the standard errors of the means. Due to the lower availability of polyclonal serum IgG, mice from this experimental group were treated up to the 6th month of age. (c) Percentage of survival in the different experimental groups. The results shown in (a), (b) and (c) were compared using the Mann-Whitney or Tukey tests $\left({ }^{\star} P \leq 0 \cdot 05,{ }^{* *} P \leq 0 \cdot 01\right)$.

Table 1. Severity of nephritis in NZB/W mice after different treatments

\begin{tabular}{|c|c|c|c|c|c|c|c|}
\hline \multirow[b]{2}{*}{ Treatment } & \multirow[b]{2}{*}{$n$} & \multicolumn{6}{|c|}{ Nephritis grade } \\
\hline & & $0+$ & $1+$ & $2+$ & $3+$ & $4+$ & $(3+)+(4+)$ \\
\hline PBS & 7 & 0 & 0 & 28.57 & 28.57 & $42 \cdot 86$ & $71 \cdot 43$ \\
\hline IgG2a (5D11) & 4 & 0 & 0 & 25 & 25 & 50 & $75 \cdot 00$ \\
\hline $\begin{array}{c}\text { Anti-NK1.1 } \\
\text { (PK136) }\end{array}$ & 11 & 0 & $36 \cdot 36$ & $18 \cdot 18$ & $27 \cdot 27$ & $18 \cdot 18$ & $45 \cdot 45$ \\
\hline $\begin{array}{l}\text { Purified } \\
\text { serum IgG }\end{array}$ & 5 & 0 & 0 & 40 & 40 & 20 & 60 \\
\hline
\end{tabular}

Mice were 10 months of age at the time of death. Sections from both kidneys were studied.

Values are percentages.

IgG2a, immunoglobulin G2a; PBS, phosphate-buffered saline.

in the progression of lupus disease by promoting the survival of self-reactive $B$ cells and their differentiation to plasmablasts and increasing immunoglobulin secretion. ${ }^{24}$ For this reason, we examined the production of BAFF/BLyS by spleen cells in the different experimental groups. To further study, the possible sources and determine the cells responsible for BAFF/BLyS production, pooled spleen or lymph node cells from four experimental groups of 6- to 8month-old NZB/W mice treated with anti-NK1.1 $(n=4)$, unrelated $\operatorname{IgG} 2 \mathrm{a}(n=4)$, polyclonal $\operatorname{IgG}(n=3)$ or PBS $(n=3)$ for a period of 4 weeks, were studied for the intracellular presence of this cytokine by FACS. Figure 2(a) (upper left contour FACS plot panel) shows that in vivo IgG2a (in either control 5D11 or anti-NK1.1 PK-136-treated animals) administration increased the percentage of $\mathrm{CD}^{+}$and $\mathrm{CD}^{+} \mathrm{T}$ cells producing BAFF/BLyS. In addition, we have detected a large proportion of spleen $B$ cells (Fig. 2a, upper right contour plot panel) and dendritic cells (Fig. 2a, histograms) producing BAFF/BLyS in IgG2atreated NZB/W mice. This experiment was repeated using the same number of animals per group, and the percentage of spleen or lymph node cell phenotypes positive for BAFF/ BLyS was recorded for each mouse in the experimental groups. These results are shown in Fig. 2(b) (bar chart). Figure 2(c) shows that supernatants from non-stimulated spleen cells from NZB/W mice treated for 1 month with purified IgG2a (obtained from 5D11 or PK136 hybrido- 

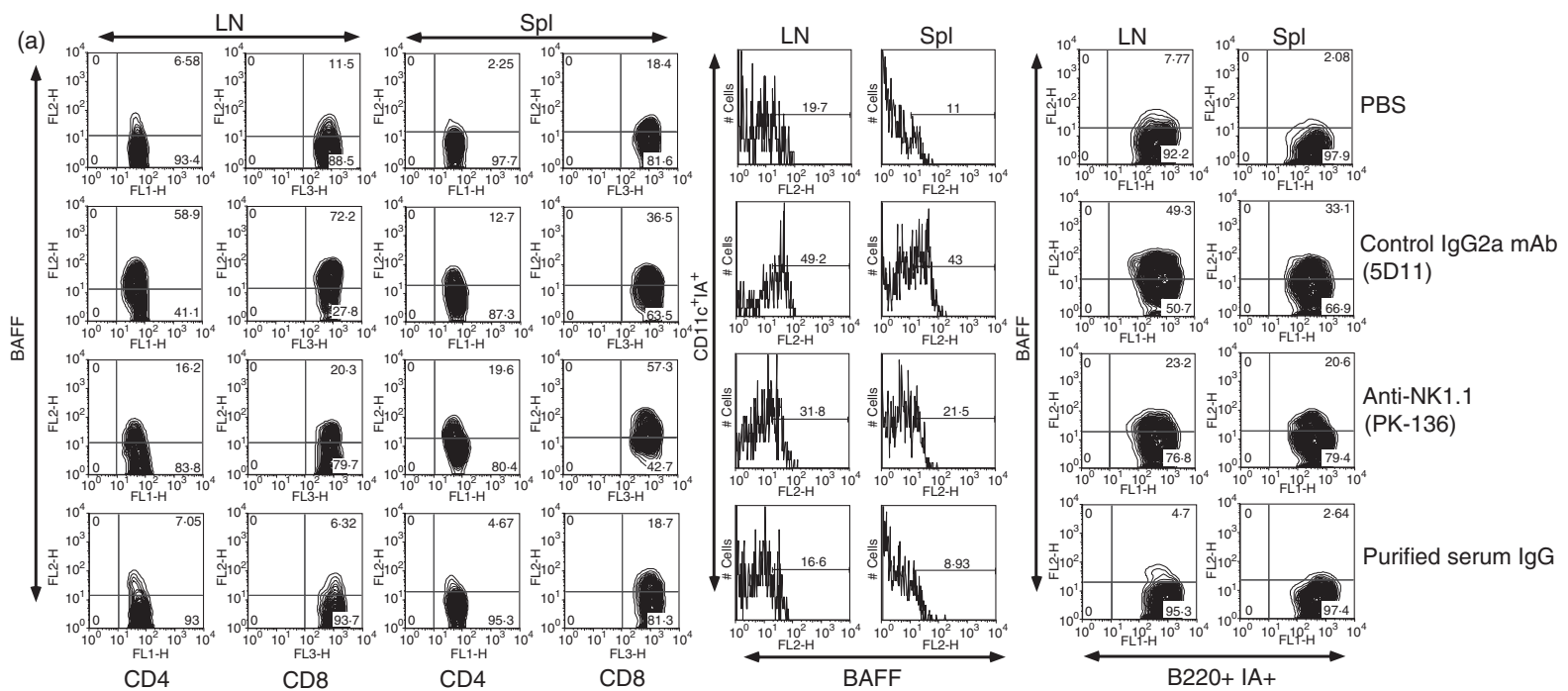

(b)
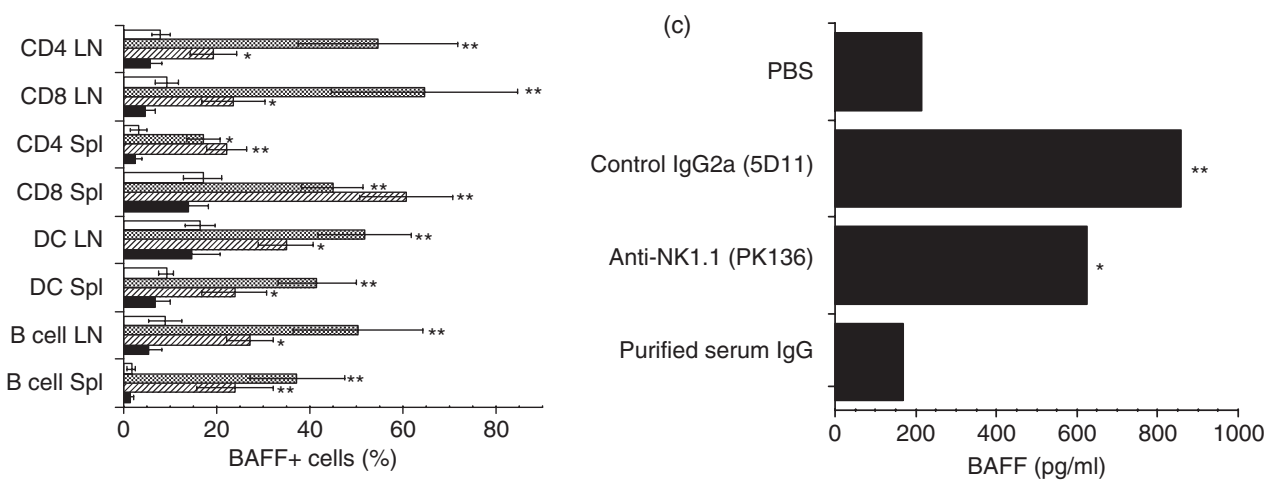

Figure 2. Immunoglobulin G2a (IgG2a) monoclonal antibodies (mAbs) induce the production of BAFF/BLyS in NZB/W mice. Spleen (Spl.) or lymph node (L.N.) cells from NZB/W mice treated with phosphate-buffered saline (PBS), control IgG2a mAb (5D11), anti-NK1.1 mAb (PK136) and polyclonal serum IgG were counted, stained and evaluated by fluorescence-activated cell sorter (FACS) as described in the Materials and methods section. Frequencies of cells producing BAFF/BLyS inside an electronically gated cell population [T cells $\left(\mathrm{CD} 4^{+}\right.$and $\left.\mathrm{CD} 8^{+}\right)$, dendritic cells $\left(\mathrm{CD} 11 \mathrm{c}^{+} \mathrm{IA}^{+}\right)$or B lymphocytes $\left.\left(\mathrm{B} 220^{+} \mathrm{IA}^{+}\right)\right]$are shown in the upper contour plots and histograms (a). Numbers inside plots and histograms represent the relative frequencies of each cell subpopulation. Contour plots and histograms are representative of one experiment, where spleen or lymph node cells were pooled for each experimental group (three to four animals/group). One independent experiment was carried out in which spleen or pooled lymph nodes cells from each mouse in the group were stained. These data were used to calculate the frequencies of each cell population ( $n=3$ or $n=4$ mice/group). These results are shown in the bar chart (b). NZB/W mouse groups are represented as follows: mice treated with phosphate-buffered saline (PBS), open bars; with anti-NK1.1 mAb, hatched bars; with control IgG2a mAb closed grey bars; with polyclonal serum IgG, closed black bars. Horizontal bars represent the standard deviations of the mean. Results were compared, using Student's $t$-test $\left({ }^{*} P \leq 0 \cdot 05,{ }^{* *} P \leq 0 \cdot 01\right)$. Data in (c) represent one experiment out of two, showing the amount of BAFF/BLyS found in supernatants from non-stimulated spleen cell cultures. Cells were cultured in vitro, as described in the Materials and methods section. Bars represent the mean of the amount of BAFF/BLyS measured in supernatants from triplicate cultures. Mann-Whitney test was used to compare the indicated groups with the control, PBS-treated group $\left({ }^{*} P \leq 0 \cdot 05,{ }^{* *} P \leq 0 \cdot 01\right)$.

mas) contained detectable levels of BAFF/BLyS measured by a sandwich ELISA. BAFF production was detected in very low levels in supernatants obtained from splenic cells derived from PBS- or polyclonal IgG-treated NZB/W mice.

\section{IgG2a $\mathrm{mAb}$ and Toll-4 ligand (LPS) are potent inducers of BAFF/BLyS production by $\mathrm{T}$ and $\mathrm{B}$ cells from NZB/W mice}

Traces of LPS frequently contaminate mAb preparations; the mAb preparations used in this study contained a small but significant amount of LPS (usually $1-2 \mathrm{ng} / \mathrm{ml}$ ). Because LPS is known to elicit cytokine secretion from various immune cell types, we designed experiments to determine if the above IgG2a mAb BAFF-inducer effect could be attributed to the LPS contamination in our $\mathrm{mAb}$ preparations. Figure 3(a) (left contour plot panel and histograms) shows that in mice treated with a control IgG1 mAb the percentages of BAFF-producing $\mathrm{T}$ or $B$ splenic cells did not increase like they did with the administration of IgG2a mAb. However, the repeated in vivo administration of minute amounts of LPS could 


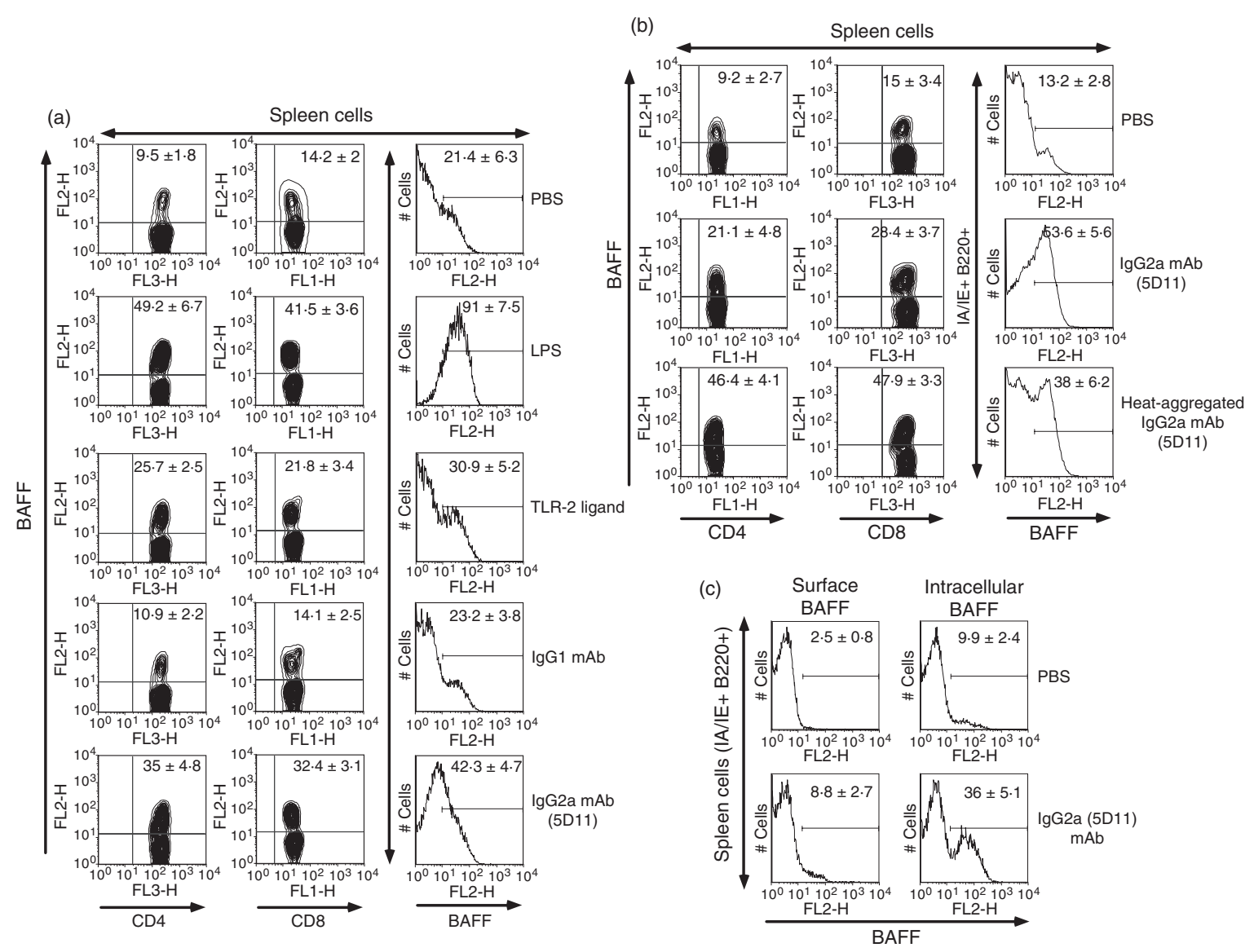

Figure 3. Immunoglobulin G2a monoclonal antibody (IgG2a mAb) and Toll-4 ligand (lipopolysaccharide; LPS) are potent inducers of BAFF/ BLyS production by $\mathrm{T}$ and $\mathrm{B}$ cells from NZB/W mice. In the left contour plot and histogram (a), spleen cells from NZB/W mice treated with PBS, LPS, Toll-like receptor-2 ligand (P3C), irrelevant IgG1 mAb (IH1) or irrelevant IgG2a mAb (5D11) were stained and evaluated by fluorescence-activated cell sorter as described in the Materials and methods section. In the right upper contour plot and histogram (b) spleen cells from $\mathrm{NZB} / \mathrm{W}$ mice treated with PBS, control IgG2a mAb (5D11) or heat-aggregated IgG2a mAb (5D11) were analysed as above. In the lower right histogram (c), spleen cells from NZB/W mice treated with PBS or control IgG2a mAb (5D11) were stained for B-cell markers (IA/IE ${ }^{+}$B220 ${ }^{+}$) followed by surface (left histograms) or intracellular (right histograms) staining with anti-BAFF-phycoerythrin mAb. Numbers inside contour plots and histograms represent the mean \pm SEM of BAFF-producing cells inside the respective subpopulations. Contour plots and histograms are representative of one typical mouse for each experimental group (three to four animals/group). Mann-Whitney test was used to compare the indicated groups with the control group $\left({ }^{*} P \leq 0 \cdot 05,{ }^{* *} P \leq 0 \cdot 01\right)$.

strongly increase the frequency of BAFF-producing splenic $\mathrm{T}$ and $\mathrm{B}$ cells. Indeed, LPS had the strongest stimulatory capacity when compared to IgG2a mAb or to a Toll-2 ligand (P3C). P3C significantly increased the percentages of $\mathrm{T}$ cells expressing BAFF, but had little or no effect on B cells. To study further the activity of $\operatorname{IgG} 2 \mathrm{a} \mathrm{mAb}$ in the stimulation of BAFF production by $\mathrm{T}$ and $\mathrm{B}$ cells, heat-aggregated or soluble IgG2a mAb preparations from the same batch of $\mathrm{mAb}$ were used to treat NZB/W mice for 1 month. Figure 3(b) (upper right contour plot panel) shows that heat aggregation of IgG2a mAb could potentiate the IgG2a activity by increasing the frequency of BAFF-producing $T$ cells. On the other hand, the frequency of $\mathrm{B}$ cells producing
BAFF after this treatment was slightly decreased compared with that after treatment with soluble IgG2a preparation (Fig. 3b, upper right histograms). Considering the possibility that the detection of BAFF-positive $\mathrm{B}$ cells in these assays could be related to the binding of this cytokine to receptors on the B-lymphocyte surface and not to its production by the B cells themselves, surface and intracellular stainings were performed and compared. Figure 3(c) (lower right histogram panel) shows that the frequency of B cells stained for surface BAFF expression was much lower than the frequency of $B$ cells with intracellular BAFF staining, showing that B cells may express BAFF at the cell surface, although at low frequencies. 
NK T cells from aged NZB/W mice, when transferred to young mice, accelerate the production of antidsDNA and have a direct helper activity for autoreactive $B$ cells in vitro

The data presented above indicate that long-term depletion of NK1.1 $1^{+}$cells ameliorates lupus-like symptoms in aged NZB/W mice. However, the use of anti-NK1.1 mAb depletes NK1.1 ${ }^{+} \mathrm{CD}^{-}$cells as well as NK T cells. Therefore, to better clarify this issue, we have transferred purified NK $\mathrm{T}$ cells obtained from young or aged NZB/W mice to two separate groups of young $\mathrm{NZB} / \mathrm{W}$ mice $(n=3$ mice/group). In addition, one control, agedmatched group of young $\mathrm{NZB} / \mathrm{W}$ mice $(n=3$ mice/ group) received only PBS instead of $\mathrm{NK} T$ cells. Figure 4(a) shows that young NZB/W mice that received old NZB/W NK T cells produced higher titres of antibodies to dsDNA than control, aged-matched mice, indicating that NK T cells from aged mice are involved in the development of lupus-like disease in this experimental model. However, NK T cells from young NZB/W mice were unable to modify the pattern of anti-dsDNA produced by young recipient mice. To further study NK T-cell helper activity in this model, purified NK T cells from aged mice were cocultured with B cells in vitro. After 7 days in culture, the supernatants were evaluated for the presence of anti-dsDNA. Figure 4(b) shows that NK $\mathrm{T}$ cells from aged NZB/W mice were able to help B cells to produce autoantibodies - confirming the direct helper activity of NK T cells on B cells. Although some helper activity could be demonstrated in this in vitro assay, for NK T cells derived from young NZB/W mice this was only evident at the highest effector : target ratio $(1: 1)$.

In vivo depletion of NK1.1+ cells diminished the production of IL-16 by spleen and liver mononuclear cells upon in vitro stimulation.

IL-16 is a cytokine produced in large amounts during the active phase of lupus disease in humans, and is considered a marker for disease activity. ${ }^{25,26}$ Therefore, we evaluated the production of this cytokine in animals that were chronically depleted of NK cells. For these experiments, one group of young C57BL/6 mice $(n=4)$, one group of young $\mathrm{NZB} / \mathrm{W}$ mice $(n=4)$ and four groups of aged NZB/W mice treated with anti-NK1.1 $(n=4)$, unrelated IgG2a (clone 5D11) $(n=3)$, polyclonal IgG $(n=3)$ or PBS $(n=4)$ were used. Aged NZB/W animal groups used in these experiments were selected from larger groups of NZB/W mice that had been treated with the reagents mentioned above since they were $6-8$ weeks old. Mice within these experimental groups that survived for 11 months were killed and their spleen and liver mononuclear cells were used in the following studies. Figure 5(a) shows that IL-16 was barely detected in
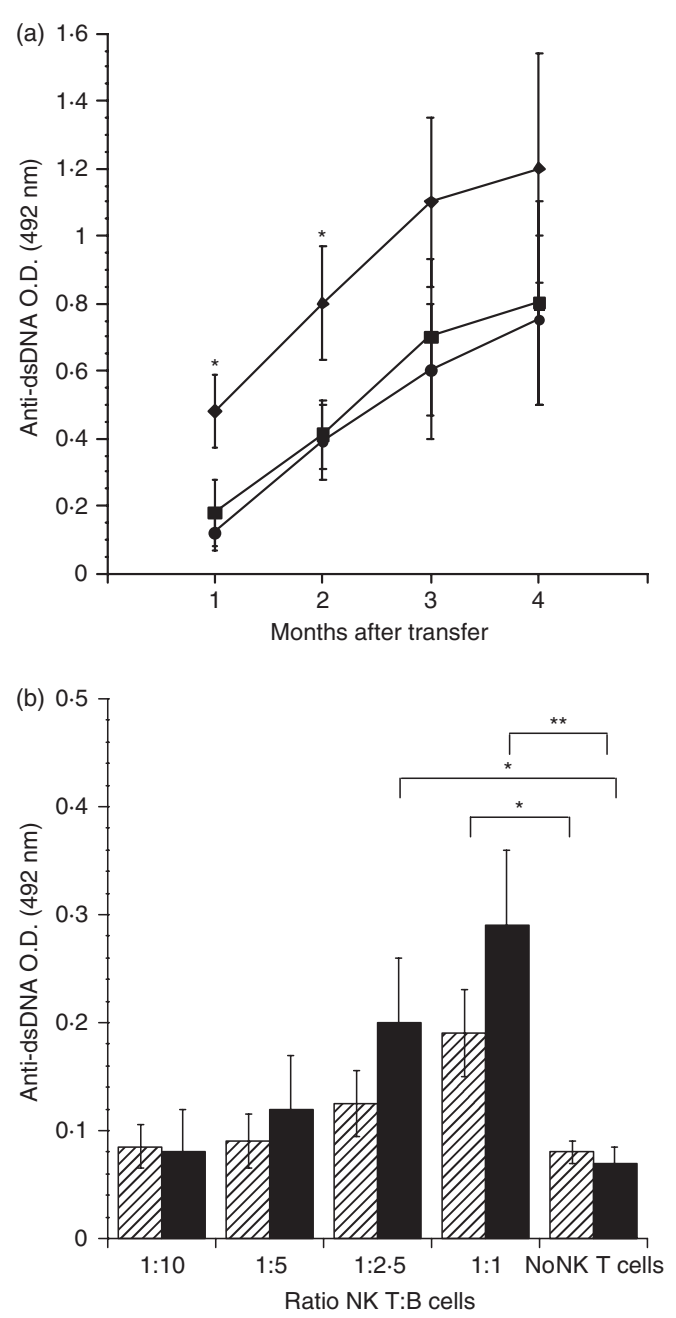

Figure 4. Natural killer (NK) T cells from aged NZB/W mice accelerate the production of anti-dsDNA when transferred to young mice, and have a direct helper activity for autoreactive $\mathrm{B}$ cells, in vitro. (a) Levels of dsDNA-specific antibodies in young NZB/W mice transferred with enriched NK $\mathrm{T}$ cells from aged NZB/W animals at different time-points after transfer, as described in the Materials and methods section. Anti-dsDNA antibody levels are shown as optical densities (ODs). Sera were compared at a single dilution (1:100). Diamonds represent young NZB/W mice transferred with NK T cells from aged NZB/W mice. Squares and circles represent young NZB/W mice transferred with NK T cells from young NZB/W mice or injected with phosphate-buffered saline (PBS), respectively. Results express the mean \pm SD of ODs. The Mann-Whitney test was used to compare groups in each point. ${ }^{\star} P \leq 0 \cdot 05$. (b) Levels of dsDNA-specific antibodies in culture supernatants. Purified $\alpha \beta^{+} \mathrm{NK} 1.1^{+} \mathrm{T}$ cells from young (hatched bars) or aged (closed black bars) NZB/W mice were titrated in cultures containing a splenic B-cell-enriched population from NZB/W mice that were 3-4 months old. Cultures were performed in the presence of soluble anti-CD3 monoclonal antibody, as described in the Materials and methods section. After 7 days, supernatants were assayed for the presence of dsDNA-specific antibodies by enzyme-linked immubosorbent assay. Results express the mean \pm SD of ODs obtained from triplicate cultures. Results were compared by Student's $t$-test $\left({ }^{\star} P \leq 0 \cdot 05,{ }^{\star *} P \leq 0 \cdot 01\right)$. 


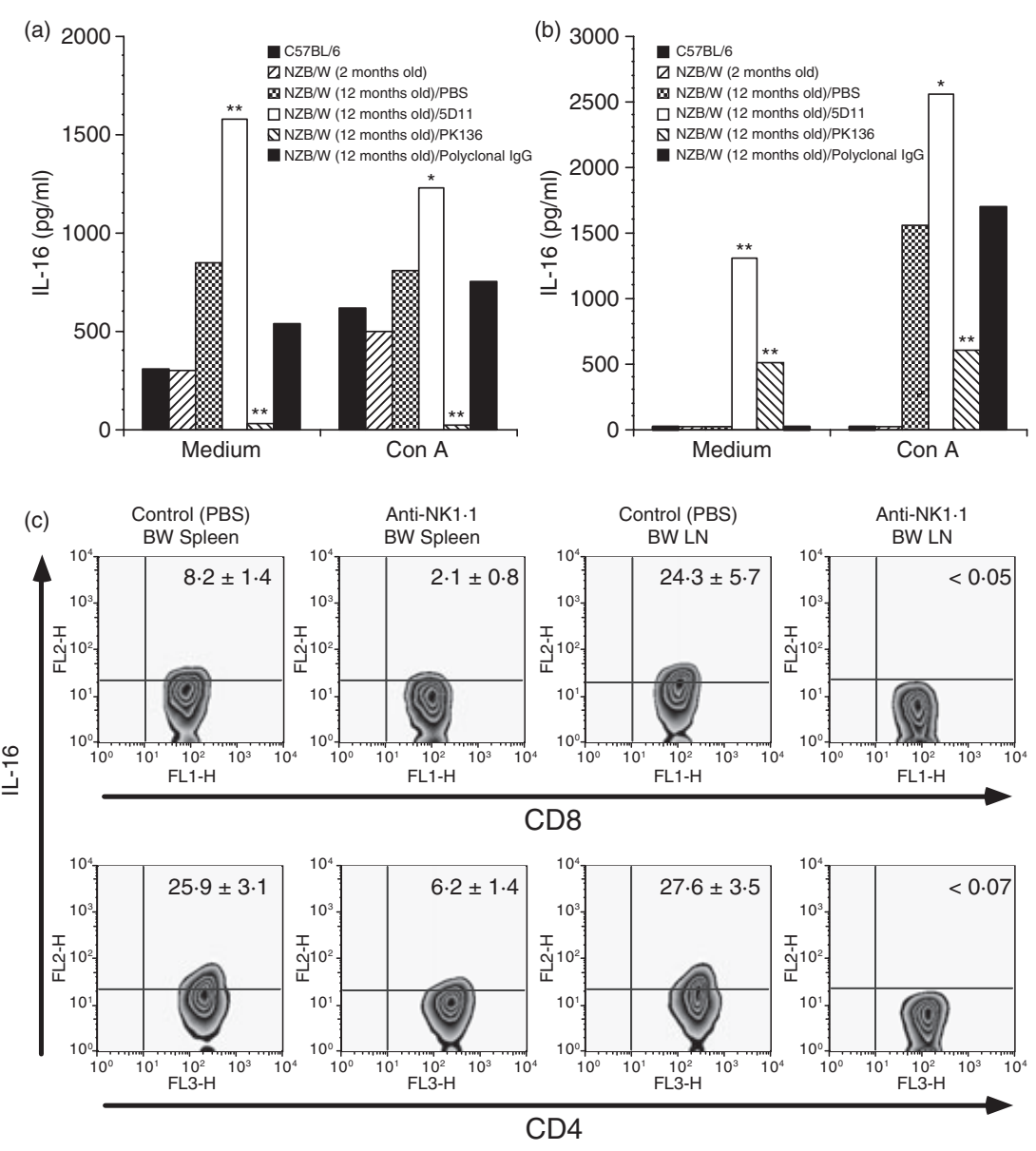

Figure 5. In vivo depletion of NK1.1 $1^{+}$cells diminishes the production of interleukin-16 (IL-16) by splenic and liver mononuclear cells upon in vitro stimulation. Spleen cells or liver mononuclear cells from the different NZB/W mouse groups or one control group of young C57BL/6 mice were cultured in vitro in the presence of medium alone or stimulated with concanavalin A (Con A), as described in the Materials and methods section. Spleen-derived or liver-derived mononuclear cells from three or four mice from each experimental group were pooled and used to prepare the cell suspensions. The amount of IL-16 (pg/ml) produced by spleen cells (a) or liver mononuclear cells (b) in the different experimental groups after $48 \mathrm{hr}$ of culture are shown. IL-16 was measured by enzyme-linked immunosorbent assay, as described in the Materials and methods section. Columns represent the mean of the amount of IL-16 from triplicate cultures. The data are from one of two experiments with similar results. Zebra plots (c) show the percentage of CD8 (upper plots) or CD4 (lower plots) T cells producing IL-16 in the spleen (BW spleen) or lymph nodes (BW L.N.) of NZB/W mice treated with phosphate-buffered saline (PBS) or anti-NK1.1 monoclonal antibody. Experiments were performed in 11-month-old animals. Treatment with anti-NK1.1 was performed as described in the Materials and methods section and it was continued up to the day the mice were killed. Numbers in the plots represent mean \pm SEM of three or four mice per group. The Mann-Whitney test was used to compare groups $\left({ }^{\star} P \leq 0 \cdot 05,{ }^{* *} P \leq 0 \cdot 01\right)$.

cell-culture supernatants from spleen cells derived from NK-depleted NZB/W mice when the cells were cultured for $48 \mathrm{hr}$ in complete medium alone or with concanavalin A stimulation. NZB/W mice that were treated with the control IgG2a (5D11) mAb showed the highest production of IL-16 by splenic cells. It is also interesting to note that the production of IL-16 was significantly diminished in supernatants derived from mononuclear liver cells from NZB/W mice that were treated with anti-NK1.1 mAb (Fig. 5b). Again, mononuclear liver cells from mice treated with control IgG2a (5D11) mAb produced the highest levels of IL-16. To verify the source of IL-16 production, intracellular stainings were performed in cultured spleen and lymph node $\mathrm{T}$ cells, after an overnight period in the presence of Brefeldin-A without further stimulation. The zebra plots in Fig. 5(c) show that $\mathrm{CD} 4 \mathrm{~T}$ cells were the major source of IL-16 in NZB/W mice and that $\mathrm{CD} 8 \mathrm{~T}$ cells were a secondary source. Again, the long-term treatment of these mice with anti-NK1.1 mAb reduced the frequencies of spleen and lymph node $\mathrm{T}$ cells that produce IL- 16 .

\section{Discussion}

It has been proposed that NK $\mathrm{T}$ cells are involved in the onset of murine lupus-like disease by promoting the 
production of autoantibodies. ${ }^{6,13,27}$ In spite of this, some studies have also suggested that NK T cells could play a protective role in lupus-like disease, especially in early life, when NZB/W mice do not show signs of active disease. ${ }^{18}$ Using an IgG2a mAb (PK-136) to deplete NK cells and an appropriate control $\mathrm{mAb}$, we have demonstrated that some of the effects that could have been attributed to NK cells can be, surprisingly, ascribed to the IgG2a mAb isotype. For instance, as shown in Fig. 1, NZB/W mice treated with anti-NK1.1 or a control IgG2a mAb had increased serum levels of anti-dsDNA and increased proteinuria sharply after the initiation of the in vivo treatment, an effect that was not seen with the use of polyclonal serum IgG or PBS. One of the possible mechanisms by which IgG2a mAbs could exert such a biological effect would be by inducing the secretion of BAFF/BLyS by $T$ and $B$ cells from the NZB/W mice, as shown in Fig. 2. BAFF/BLyS is a cytokine that is highly increased in human lupus, and its blockage may ameliorate the course of the pathology. ${ }^{28}$ It is particularly interesting that NZB/ $\mathrm{W}$ B cells produce BAFF/BLyS in response to IgG2a treatment. In theory, the production of BAFF/BLyS by the B cells themselves would imply in an autonomous, autocrine effect of this cytokine in B-cell activation/differentiation during the development of lupus-like disease in $\mathrm{NZB} / \mathrm{W}$ mice and would preferentially favour self-reactive $\mathrm{B}$ cells in this experimental model, as already proposed by previous work..$^{29}$ BAFF messenger RNA production could not be detected in human peripheral blood $\mathrm{CD} 20^{+}$cells. $^{30}$ However, there are considerable differences between circulating B cells and B cells that are parked in lymphoid organs. ${ }^{31-33}$ These differences may explain the absence of BAFF messenger RNA in peripheral blood B cells from patients with systemic lupus erythematosus. However, a recent study has, unequivocally, shown BAFF production by mouse B cells upon LPS stimulation. ${ }^{34}$ Contamination with protein-G or LPS in our $\mathrm{mAb}$ preparation could be responsible for the BAFF production, as protein- $G$ and LPS are B-cell polyclonal activators and induce rapid onset of lupus-like disease. ${ }^{35}$ We were unable to check the amount of protein-G in our preparations. Nevertheless, polyclonal IgG from BALB/c sera was purified in the same way as our mAbs and did not induce an early onset of lupus-like disease in NZB/W mice, therefore suggesting that protein-G contamination was not responsible for raising anti-dsDNA and proteinuria levels. Another possibility would be that $5 \mathrm{D} 11 \mathrm{mAb}$ would bind to a given cell population that could mediate these biological effects. Biotin-labelled 5D11 mAb, which is an anti-human carcinoembryonic antigen antibody, was used to stain thymocytes, splenocytes and bone marrow cells from NZB/W and C57BL/6 mice and no particular staining above background levels could be seen (supplementary Fig. S1, panel B). However, the levels of endotoxin in our antibody preparations were, as evaluated by the Limulus assay, between 1 and $2 \mathrm{ng} / \mathrm{ml}$. This level of contamination led us to investigate the biological activity of similar amounts of LPS when injected in NZB/W mice for the same length of time as in the experiments shown in Fig. 2. The results presented in Fig. 3 show that as little as $2 \mathrm{ng} /$ injection three times per week for a total period of 4 weeks was enough to increase the percentage of $\mathrm{T}$ cells (three- to fourfold) and $\mathrm{B}$ cells (ninefold) that produced BAFF. In fact, after LPS in vivo treatment, virtually all splenic B cells from NZB/W mice produced BAFF. A Toll-2 ligand (P3C) was used as a control in the same dose as the Toll-4 ligand (LPS) and only a modest increase in the percentage of $\mathrm{T}$ cells producing BAFF was detected. Therefore, LPS was characterized as a major BAFF inducer in this system and could be responsible for the biological effects of the IgG2a mAbs used in this study. However, we could not obtain comparable results by using mAbs belonging to different immunoglobulin subclasses. For instance, in vivo administration of an unrelated $\operatorname{IgG} 1 \mathrm{mAb}$ prepared in the same way as the IgG2a mAb did not increased the percentages of $\mathrm{T}$ and $\mathrm{B}$ cells producing BAFF in NZB/W mice, suggesting that the biological effect of the IgG2a mAb preparation was isotype-specific (Fig. 3). One intriguing question is why should exogenous IgG2a affect the development of lupuslike disease in an animal that already has about $4 \mathrm{mg}$ of endogenous $\mathrm{IgG} 2 \mathrm{a} / \mathrm{ml}$ of serum. One possibility to be considered is that the effect of the exogenous IgG2a is mediated by a small proportion of the immunoglobulin that has been aggregated by its in vitro manipulation and injection in the peritoneal cavity, mimicking antigen-IgG complexes. This hypothesis was tested and the results showed that the heat-aggregated IgG2a mAb preparation had significantly more biological effects compared with the parental soluble IgG2a preparation in the induction of BAFF production by $\mathrm{T}$ cells (and not by $\mathrm{B}$ cells). Heat aggregation does not diminish or destroys LPS activity, but rather potentiates $\mathrm{Fc}$ biological activities, ${ }^{36,37}$ indicating that, at least on $\mathrm{T}$ cells, the effect of our IgG2a preparation was Fc-dependent and not LPS-dependent. These experiments, taken together, suggest that different pathways stimulate $\mathrm{T}$ and $\mathrm{B}$ cells to produce BAFF, and they may highlight the importance of a different class of Fc-receptor in this activity. BAFF/BLyS production by $\mathrm{T}$ cells was previously shown in patients with systemic lupus erythematosis. ${ }^{38}$ In non-autoimmune mouse strains, BAFF/BLyS is produced mostly by dendritic cells and macrophages. ${ }^{39}$ The presence of a large percentage of $\mathrm{T}$ cells producing BAFF/BLyS when NZB/W mice were injected with IgG2a may constitute a deregulation of BAFF/BLyS production as the result of an inherent over/ underexpression of a special class of molecules belonging to the Fc $\gamma$-receptor family in those mice. ${ }^{4-42}$ In addition, or alternatively, this effect could be the result of genetic polymorphic variants of some of the components 
of the Fc $\gamma$-receptor family that are related to susceptibility to lupus disease. ${ }^{43}$ The recent description of a new component of this family (Fc $\gamma$ RIV) that binds to IgG2a/ IgG2b and has activating properties instead of downregulatory effects is of particular interest. ${ }^{42}$ Therefore, it seems appropriate to discuss that the biological effects ascribed here to IgG2a could be related to its Fc portion$\mathrm{Fc}$ receptor $(\mathrm{FcR})$ interaction. In addition, it might be possible that BAFF/BLyS may increase the survival of autoreactive IgG2a-producing $B$ cells in response to interferon- $\gamma$ (a potent inducer of B-cell IgG2a isotype switching). This cytokine and its related IgG2a subclass are directly linked to lupus activity and exacerbation., ${ }^{6,44}$ Consequently, the IgG2a/IgG2b Fc $\gamma$ RIV could be a candidate molecule to aggravate and/or initiate lupus disease. One additional possibility remains unexplored: the introduction of $\operatorname{IgG} 2 \mathrm{a}$ into the peritoneal cavity could perhaps stimulate lymphocytes of the intestinal mucosa-associated lymphoid tissue, which differ from lymphocytes in other lymphoid organs in terms of their phenotype pattern and receptor specificity. ${ }^{45}$ This possibility is amenable to future investigations.

It should be noted that our preparation of $\mathrm{BALB} / \mathrm{c}$ polyclonal IgG also contained high levels of IgG2a, but its in vivo administration did not raise the levels of antidsDNA as the IgG2a mAbs did. In addition, the IgG1 $m A b$ preparation used in our studies contained low amounts of LPS and was ineffective at increasing the percentage of BAFF-producing $\mathrm{T}$ and $\mathrm{B}$ cells. These findings could indicate a predominantly negative regulatory role of other IgG isotypes by interacting with the inhibitory Fc $\gamma$ RIIB, as proposed elsewhere. ${ }^{46}$ Alternatively, this could be linked to the presence of a small amount of IgG with heavily sialylated Fc portion in these IgG preparations, as suggested previously. ${ }^{47}$

In spite of the initial worsening of lupus-like disease after the administration of the control IgG2a mAb or IgG2a anti-NK1.1 mAbs, the long-term depletion of $\mathrm{NK}$ cells stabilized the progression of the disease in NZB/W mice, resulting in diminished kidney lesions and proteinuria as well as prolonged survival. These observations indicate that $\mathrm{NK}$ cells are actively contributing to the development of the disease, especially in aged NZB/W mice. It is known that $\mathrm{NK} \mathrm{T}$ cells from aged NZB/W mice are endowed with a helper B-cell activity that is important in initiating or boosting the production of anti-DNA autoantibodies. ${ }^{6}$ We confirm and extend these previous results by showing that young NZB/W mice transferred with NK $\mathrm{T}$ cells from aged mice, but not those receiving cells from young NZB/W mice, had an accelerated disease onset. Additionally, NK $\mathrm{T}$ cells from aged $\mathrm{NZB} / \mathrm{W}$ mice were more effective in providing B-cell helper activity in vitro than their counterpart obtained from young mice. This might be related to functional differences between young and aged mouse NK T cells and/ or to the presence of an anomalous set of TCR in the NK T cells of old animals. ${ }^{16}$ In fact, a recent study shows that NK $\mathrm{T}$ cells from aged NZB/W mice are endowed with a natural B-cell helper activity, leading to the production of IgM and IgG autoantibodies and abnormal behaviour in comparison with NK T cells from young NZB/W mice. ${ }^{48}$

Depletion of NK cells also led to diminished production of IL-16 by concanavalin A-stimulated spleen cells or mononuclear cells derived from liver. An increased production of IL-16 has being described in patients with systemic lupus erythematosus and its increase in the serum correlated with disease activity. ${ }^{25,26}$ It is possible, therefore, that $\mathrm{NK} 1.1^{+}$cells are responsible for IL-16 production in NZB/W mice. However, in preliminary experiments, we were not able to detect any production of IL-16 by purified NK T cells in culture upon different forms of stimulation (data not shown), suggesting that these cells are not a major source of IL-16, but rather are important for IL-16 production by other cell types. In fact, the major source of IL-16 in NZB/W mice was CD4 $\mathrm{T}$ cells in both spleen and lymph nodes (Fig. $5 \mathrm{c}$ ).

In conclusion, we provide evidence to support a role of NK $1.1^{+}$cells, more precisely NK T cells, in the development of lupus-like disease in NZB/W mice. In addition, our data support the hypothesis that NK T cells may have a dual role in the development of this disease in mice because NK $\mathrm{T}$ cells from aged mice appear to be pathogenic, contributing to aggravate the disease, whereas NK T cells from young mice, considering other published studies, seem to have a protective or neutral role in the development of the disease, as previously suggested. ${ }^{6}$ In addition, we have shown that in vivo administration of immunoglobulin of the IgG2a subclass or LPS induce the production of high amounts of BAFF/BLyS, which might be related to the acceleration of lupus-like disease in NZB/W mice. These observations, suggest that some Fc receptor family molecules, with activating biological activities, may be important targets for blocking procedures in systemic lupus erythematous ${ }^{49}$ and that LPS is a very potent agent to induce BAFF production by $\mathrm{T}$ and $\mathrm{B}$ cells. It is interesting to note that a disruption of the intestinal immunological barrier as the result of gut-associated lymphoid tissue (GALT) depletion was described in NZB/W mice. ${ }^{50}$ This parallels the GALT depletion in human immunodeficiency virus infection where circulating LPS is found. ${ }^{51}$ This situation has been shown to be a major cause of the polyclonal immune system activation found during this viral infection. Although it is necessary to show these conditions for patients with lupus and admit that there may be inherent differences in functional behaviour, signalling pathways and Toll-like receptor/FcR receptor expression between mouse and human cells, the reconstitution of the GALT function and/or the development of Toll-like receptor-4 antagonists for clinical use should be investigated as useful strategies to control systemic lupus erythematosus in humans. ${ }^{52,53}$ 


\section{Acknowledgements}

We are in debt to Dr Lain Pontes de Carvalho, Dr Thiago L. Carvalho and Dr Owen Williams for critical reading of the manuscript. We also thank Dr Lain Pontes de Carvalho for the gift of IH1 monoclonal antibody ascites. J.M., M.M. and F.C. are recipients of $\mathrm{CNPq}$ research scholarships. This work was supported by grants from FAPESP (95/9379-2 and 97/06225-0) and CNPq (305835/ 2003-3). This study contains results obtained during the thesis work of E.P. and A.M. A.M. is supported by a scholarship from FAPESB. The authors, spontaneously, declare no conflict of interests.

\section{References}

1 Kotzin BL. Systemic lupus erythematosus. Cell 1996; 85:303-6.

2 O'Keefe TL, Datta SK, Imanishi-Kari T. Cationic residues in pathogenic anti-DNA autoantibodies arise by mutations of a germ-line gene that belongs to a large VH gene subfamily. Eur J Immunol 1992; 22:619-24.

3 Hahn BH. Antibodies to DNA. N Engl J Med 1998; 338:1359-68.

4 Abedi-Valugerdi M, Hansson M, Moller G. Genetic control of resistance to mercury-induced immune/autoimmune activation. Scand J Immunol 2001; 54:190-7.

5 Ehlers M, Fukuyama H, McGaha TL, Aderem A, Ravetch JV. TLR9/MyD88 signaling is required for class switching to pathogenic IgG2a and 2b autoantibodies in SLE. J Exp Med 2006; 203:553-61.

6 Zeng D, Liu Y, Sidobre S, Kronenberg M, Strober S. Activation of natural killer $\mathrm{T}$ cells in NZB/W mice induces Th1-type immune responses exacerbating lupus. J Clin Invest 2003; 112:1211-22.

7 Wofsy D, Chiang NY, Greenspan JS, Ermak TH. Treatment of murine lupus with monoclonal antibody to L3T4. I. Effects on the distribution and function of lymphocyte subsets and on the histopathology of autoimmune disease. J Autoimmun 1988; 1:415-31.

8 Sharabi A, Azulai H, Sthoeger ZM, Mozes E. Clinical amelioration of murine lupus by a peptide based on the complementarity determining region-1 of an autoantibody and by cyclophosphamide: similarities and differences in the mechanisms of action. Immunology 2007; 121:248-57.

9 Forestier C, Molano A, Im JS et al. Expansion and hyperactivity of CD1d-restricted NKT cells during the progression of systemic lupus erythematosus in (New Zealand Black $\times$ New Zealand White) $\mathrm{F}_{1}$ mice. J Immunol 2005; 175:763-70.

10 Yang JQ, Chun T, Liu H, Hong S, Bui H, Van Kaer L, Wang CR, Singh RR. CD1d deficiency exacerbates inflammatory dermatitis in MRL-lpr/lpr mice. Eur J Immunol 2004; 34:172332.

11 Sireci G, Russo D, Dieli F et al. Immunoregulatory role of Jalpha281 $\mathrm{T}$ cells in aged mice developing lupus-like nephritis. Eur J Immunol 2007; 37:425-33.

12 Sieling PA, Porcelli SA, Duong BT, Spada F, Bloom BR, Diamond $\mathrm{B}$, Hahn $\mathrm{BH}$. Human double-negative $\mathrm{T}$ cells in systemic lupus erythematosus provide help for IgG and are restricted by CD1c. J Immunol 2000; 165:5338-44.
13 Zeng D, Lee MK, Tung J, Brendolan A, Strober S. Cutting edge: a role for CD1 in the pathogenesis of lupus in NZB/NZW mice. J Immunol 2000; 164:5000-4.

14 Bendelac A, Rivera MN, Park SH, Roark JH. Mouse CD1-specific NK1 T cells: development, specificity, and function. Annu Rev Immunol 1997; 15:535-62.

15 Park SH, Chiu YH, Jayawardena J, Roark J, Kavita U, Bendelac A. Innate and adaptive functions of the CD1 pathway of antigen presentation. Semin Immunol 1998; 10:391-8.

16 Mieza MA, Itoh $\mathrm{T}$, Cui JQ et al. Selective reduction of $\mathrm{V}$ alpha $14+$ NK T cells associated with disease development in autoimmune-prone mice. J Immunol 1996; 156:4035-40.

17 Yang JQ, Saxena V, Xu H, Van Kaer L, Wang CR, Singh RR. Repeated alpha-galactosylceramide administration results in expansion of NK T cells and alleviates inflammatory dermatitis in MRL-lpr/lpr mice. J Immunol 2003; 171:4439-46.

18 Yang JQ, Wen X, Liu H, Folayan G, Dong X, Zhou M, Van Kaer L, Singh RR. Examining the role of CD1d and natural killer $\mathrm{T}$ cells in the development of nephritis in a genetically susceptible lupus model. Arthritis Rheum 2007; 56:1219-33.

19 Nomizo A, Postol E, de Alencar R, Cardillo F, Mengel J. Natural killer $\mathrm{T}$ cells are required for the development of a superantigendriven $\mathrm{T}$ helper type 2 immune response in mice. Immunology 2005; 116:233-44.

20 Nomizo A, Cardillo F, Postol E, de Carvalho LP, Mengel J. V gamma 1 gammadelta $\mathrm{T}$ cells regulate type-1/type-2 immune responses and participate in the resistance to infection and development of heart inflammation in Trypanosoma cruzi-infected BALB/c mice. Microbes Infect 2006; 8:880-8.

21 Carneiro CR, Lopes JD, Brentani MM. Carcinoembryonic antigen (CEA): production of immunoprecipitating monoclonal antibodies and development of an enzyme immunoassay. Hybridoma 1987; 6:689-92.

22 Soares NM, Santiago MB, Pontes deCarvalho LC. An improved anti-C3/IgG ELISA for quantification of soluble immune complexes. J Immunol Methods 2001; 249:199-205.

23 Aguiar PH, Borges dos Santos RR, Larangeira DF et al. A novel monoclonal antibody against canine monocytes/macrophages. Hybrid Hybridomics 2004; 23:250-7.

24 Melchers F. Actions of BAFF in B cell maturation and its effects on the development of autoimmune disease. Ann Rheum Dis 2003; 62 (Suppl. 2):ii25-7.

25 Lard LR, Roep BO, Verburgh CA, Zwinderman AH, Huizinga TW. Elevated IL-16 levels in patients with systemic lupus erythematosus are associated with disease severity but not with genetic susceptibility to lupus. Lupus 2002; 11:181-5.

26 Lee S, Kaneko H, Sekigawa I, Tokano Y, Takasaki Y, Hashimoto $\mathrm{H}$. Circulating interleukin-16 in systemic lupus erythematosus. Br J Rheumatol 1998; 37:1334-7.

27 RR EB, De Lorenzo BH, Xander P, Godoy LC, Lopes JD, da Silva NP, Sampaio SC, Mariano M. Role of distinct immune components in the radiation-induced abrogation of systemic lupus erythematosus development in mice. Lupus 2007; 16:94754.

28 Bosello S, Pers JO, Rochas C et al. BAFF and rheumatic autoimmune disorders: implications for disease management and therapy. Int J Immunopathol Pharmacol 2007; 20:1-8.

29 Noelle RJ, Erickson LD. Determinations of B cell fate in immunity and autoimmunity. Curr Dir Autoimmun 2005; 8:1-24. 
30 Morimoto S, Nakano S, Watanabe T et al. Expression of B-cell activating factor of the tumour necrosis factor family (BAFF) in $\mathrm{T}$ cells in active systemic lupus erythematosus: the role of BAFF in $\mathrm{T}$ cell-dependent $\mathrm{B}$ cell pathogenic autoantibody production. Rheumatology (Oxford) 2007; 46:1083-6.

31 Lopes-Carvalho T, Kearney JF. Development and selection of marginal zone B cells. Immunol Rev 2004; 197:192-205.

32 Lopes-Carvalho T, Kearney JF. Marginal zone B cell physiology and disease. Curr Dir Autoimmun 2005; 8:91-123.

33 Lopes-Carvalho T, Foote J, Kearney JF. Marginal zone B cells in lymphocyte activation and regulation. Curr Opin Immunol 2005; 17:244-50.

34 Chu VT, Enghard P, Riemekasten G, Berek C. In vitro and in vivo activation induces BAFF and APRIL expression in B cells. J Immunol 2007; 179:5947-57.

35 Sumegi A, Antal-Szalmas P, Aleksza M, Kovacs I, Sipka S, Zeher M, Kiss E, Szegedi G. Glucocorticosteroid therapy decreases CD14-expression and CD14-mediated LPS-binding and activation of monocytes in patients suffering from systemic lupus erythematosus. Clin Immunol 2005; 117:271-9.

36 Gao B, Wang Y, Tsan MF. The heat sensitivity of cytokineinducing effect of lipopolysaccharide. J Leukoc Biol 2006; 80:35966.

37 Augener W, Grey HM. Studies on the mechanism of heat aggregation of human gamma-G. J Immunol 1970; 105:1024-30.

38 Yoshimoto K, Takahashi Y, Ogasawara M, Setoyama Y, Suzuki K, Tsuzaka K, Abe T, Takeuchi T. Aberrant expression of BAFF in T cells of systemic lupus erythematosus, which is recapitulated by a human T cell line, Loucy. Int Immunol 2006; 18:1189-96.

39 Mackay F, Woodcock SA, Lawton P, Ambrose C, Baetscher M, Schneider P, Tschopp J, Browning JL. Mice transgenic for BAFF develop lymphocytic disorders along with autoimmune manifestations. J Exp Med 1999; 190:1697-710.

40 Fukuyama H, Nimmerjahn F, Ravetch JV. The inhibitory Fcgamma receptor modulates autoimmunity by limiting the accumulation of immunoglobulin G+ anti-DNA plasma cells. Nat Immunol 2005; 6:99-106.

41 McGaha TL, Sorrentino B, Ravetch JV. Restoration of tolerance in lupus by targeted inhibitory receptor expression. Science 2005; 307:590-3.

42 Nimmerjahn F, Bruhns P, Horiuchi K, Ravetch JV. FcgammaRIV: a novel FcR with distinct IgG subclass specificity. Immunity 2005; 23:41-51.

43 Wu J, Edberg JC, Redecha PB, Bansal V, Guyre PM, Coleman K, Salmon JE, Kimberly RP. A novel polymorphism of FcgammaRIIIa (CD16) alters receptor function and predisposes to autoimmune disease. J Clin Invest 1997; 100:1059-70.

44 Jacob $\mathrm{CO}$, van der Meide $\mathrm{PH}, \mathrm{McD}$ evitt $\mathrm{HO}$. In vivo treatment of $(\mathrm{NZB} \times \mathrm{NZW}) \mathrm{F}_{1}$ lupus-like nephritis with monoclonal antibody to gamma interferon. J Exp Med 1987; 166:798-803.

45 McGhee JR, Kunisawa J, Kiyono H. Gut lymphocyte migration: we are halfway 'home'. Trends Immunol 2007; 28:150-3.

46 Boruchov AM, Heller G, Veri MC, Bonvini E, Ravetch JV, Young JW. Activating and inhibitory IgG Fc receptors on human DCs mediate opposing functions. J Clin Invest 2005; 115:2914-23.

47 Kaneko Y, Nimmerjahn F, Ravetch JV. Anti-inflammatory activity of immunoglobulin G resulting from Fc sialylation. Science 2006; 313:670-3.
48 Takahashi T, Strober S. Natural killer T cells and innate immune B cells from lupus-prone NZB/W mice interact to generate IgM and IgG autoantibodies. Eur J Immunol 2008; 38:156-65.

49 Werwitzke S, Trick D, Sondermann P et al. Treatment of lupusprone NZB/NZW $F_{1}$ mice with recombinant soluble Fc gamma receptor II (CD32). Ann Rheum Dis 2008; 67:154-61.

50 Akadegawa K, Ishikawa S, Sato $\mathrm{T}$ et al. Breakdown of mucosal immunity in the gut and resultant systemic sensitization by oral antigens in a murine model for systemic lupus erythematosus. J Immunol 2005; 174:5499-506.

51 Brenchley JM, Price DA, Schacker TW et al. Microbial translocation is a cause of systemic immune activation in chronic HIV infection. Nat Med 2006; 12:1365-71.

52 Uehori J, Matsumoto M, Tsuji S et al. Simultaneous blocking of human Toll-like receptors 2 and 4 suppresses myeloid dendritic cell activation induced by Mycobacterium bovis bacillus Calmette-Guérin peptidoglycan. Infect Immun 2003; 71:4238-49.

53 Mullarkey M, Rose JR, Bristol J et al. Inhibition of endotoxin response by e5564, a novel Toll-like receptor 4-directed endotoxin antagonist. J Pharmacol Exp Ther 2003; 304:1093-102.

\section{Supplementary material}

The following supplementary material is available for this article:

Figure S1. Control procedures. Top contour plots (panel A) document the depletion of natural killer (NK) $\mathrm{T}$ cells in liver-derived mononuclear cells from NZB/W mice. Liver-derived mononuclear cells were used instead of spleen cells because their NK T-cell content is greater. Animals were treated with anti-NK1.1 monoclonal antibody $(\mathrm{mAb})$ for a period of 1 week, as described in the Materials and methods section. The top contour plots represent one animal that received phosphate-buffered saline (PBS; left) and an animal that received anti-NK1.1 $\mathrm{mAb}$ (right). Histograms on the right (panel B) show control stainings with 5D11 mAb. Spleen (Spl.), thymus (Thy) and bone marrow (B.M.) were stained with biotin$5 \mathrm{D} 11 \mathrm{mAb}$ and streptavidin-phycoerythrin (St-PE) or St-PE only, as described in the Materials and methods section. Histograms are for one NZB/W mouse. Bottom dot plots (panel C) show the enrichment of NK T cells and $B$ cells derived from NZB/W mice after positive selection with microbeads as described in the Materials and methods section. Plots show one typical experiment. These cells were used for in vivo transfers and in vitro experiments.

This material is available as part of the online article from: http://www.blackwell-synergy.com/

Please note: Blackwell Publishing are not responsible for the content or functionality of any supplementary materials supplied by the authors. Any queries (other than missing material) should be directed to the corresponding author for the article. 